\title{
Movement of water droplets in a layer of thermally decomposable forest fuel
}

\author{
Roman S. Volkov, Alyona O. Zhdanova*, Geniy V. Kuznetsov, and Pavel A. Strizhak \\ National Research Tomsk Polytechnic University, 634050 Tomsk, Russia
}

\begin{abstract}
This article contains results of an experimental study of the process of droplets gravitating in a layer of a typical forest fuel during its thermal decomposition. Also similar experiments were carried out in conditions of moderate temperature conditions (about $300 \mathrm{~K}$ ). Pine needles were considered as a material for study. The initial droplets' volume was varied from 90 to $900 \mu \mathrm{L}$. After analysis of experimental results we established the depths, on which water droplets can penetrate into the layer of forest combustible material (FCM). The characteristic velocities of water droplets' motion at different distances from the FCM surface were calculated. Also we determined the fraction of the mass of water consumed in the FCM layer for vaporization and cooling of the material to temperatures below the values corresponding to thermal decomposition.
\end{abstract}

\section{Introduction}

Extinguishing forest fires using aviation help is carried out mainly [1-3] due to the suppling of large amounts of water in the combustion area. In all weather conditions, suppression of pyrolysis of forest combustible material (FCM), which is named as one of the main mechanisms, is provided. At the present time the investigation of the processes occurring during the interaction of FCM with water droplets heightens the greatest interest. Currently there are no published experimental data, which describe the regularities of the heat and mass transfer processes in the porous structure of thermally decomposing FCM in conditions of water droplets' motion through a layer of such material (material is heated up to temperatures, which substantially exceed the temperature of the onset of thermal decomposition of FCM).

The aim of this work is revealing the mechanism of moving water droplets in a porous structure passing through the thermal decomposition stage of FCM based on the results of experimental studies.

\section{Experimental methods and procedures}

The experimental setup was used in carrying out of experimental research (Fig.1). We used thin-walled quartz glass cylinder with diameter $d_{\mathrm{f}} \approx 100 \mathrm{~mm}$ and height $h_{\mathrm{f}} \approx 120 \mathrm{~mm}$ for creating the model of fire seat. Pine needles were chosen as forest fuel. The density and

*Corresponding author: zhdanovaao@tpu.ru 
humidity of the FCM sample were selected as averages of possible values for fires in the boreal zone. The density was $30-35 \mathrm{~kg} / \mathrm{m}^{3}$, calculated using formula $\rho_{\mathrm{f}}=m_{\mathrm{fo}} /\left(h_{\mathrm{f}} \cdot S_{\mathrm{f}}\right)$, where $\left.S_{\mathrm{f}}=\pi \cdot\left(d_{\mathrm{f}} / 2\right)^{2}\right)$ is the cross-sectional area of the sample FCM, $\mathrm{m}^{2}$. Relative humidity of spruce needles was $7-10 \%$ calculated using formula $\gamma_{\mathrm{f}}=\left(m_{\mathrm{fw}}-m_{\mathrm{fd}}\right) / m_{\mathrm{fw}} \cdot 100$, where $m_{\mathrm{fw}}$ is the sample's weight before thermal drying, $\mathrm{g} ; m_{\mathrm{fd}}-$ is the sample's weight after thermal drying, g.

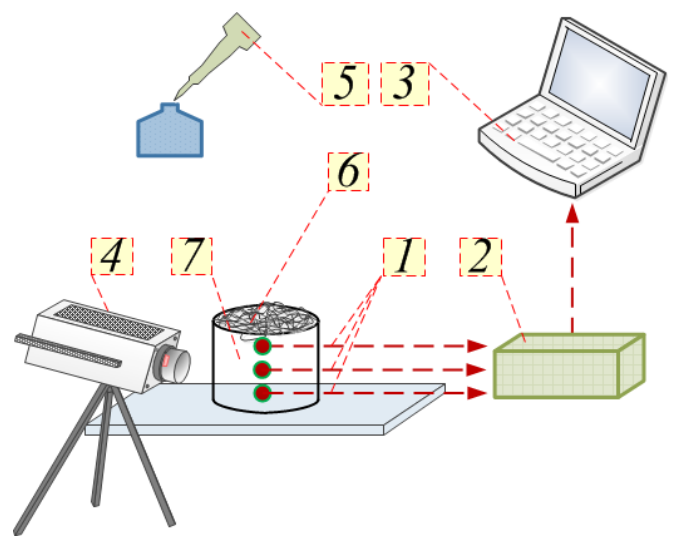

Fig. 1. A scheme of experimental setup: 1 - three low-inertia thermocouples; 2 - high-speed analog input module; 3 - workstation (PC); 4 - high-speed video camera; 5 - dispenser; 6 - FCM; 7 hollow cylinder with a hinge of FCM.

Experimental studies were carried out in two stages. At the first stage water droplets were placed on the surface of a FCM's sample that was not subject to pyrolysis. The second stage assumed similar experiments with thermally decomposed FCM. In this case, the initiation of FCM's thermal decomposition was realized using three piezo igniters. These ignited the top of the sample. After 15-20 seconds the temperature in the FCM's layer throughout the entire thickness became higher than the temperature of the onset of thermal decomposition $(400 \mathrm{~K})$.

Measurements of the distances $h$ passed by the drops and the corresponding times $t$ were carried out using two registration schemes. According to the first one, we used the high-speed analog input module 2 "National Instruments NI 9213" and three type K thermocouples installed in the FCM's layer (with temperature measurement range of 223$1473 \mathrm{~K}$, systematic error of $\pm 3 \mathrm{~K}$, and thermal inertia not exceeding $0.1 \mathrm{~s}$ ). When a drop of water hits the sensing element (or passes in the immediate vicinity of the element), the thermocouple recorded a significant temperature drop (this time indicated the achievement by a drop of the corresponding FCM's section). Such a scheme was used only in experiments with pyrolysis processes.

The second scheme for the $h(t)$ determination involved finding distances $h$ that were passed by the water drops, and the corresponding times $t$ during the analysis of the obtained video recordings. We used high-speed digital 4 CMOS video camera "Phantom V411" (with shooting frequency up to 105 frames per second and maximum resolution of $1280 \times$ 1280 pixels). Video shooting process was carried out with a frequency of 200 frames per second. The FCM layer was lighted using a specialized illumination system based on an LED matrix. We used the Tema Automotive software $[5,6]$ for continuous tracking of water drop's motion.

Random experiments' errors were determined in a way similar to the experiments $[7,8]$ and amounted to the mean values with the identical conditions $h-15 \%$. We conducted 8 12 experiments for getting accurate results. 
Also, we controlled the mass of water drops after passing through the FCM layer. For this purpose we used ViBRA HT 84RCE scales. The droplets were weighed before dropping onto the FCM sample $\left(m_{\mathrm{d} 0}\right)$ and after passing through it $\left(m_{\mathrm{de}}\right)$ for moderate temperature conditions and during thermal decomposition. The random errors of determining $m_{\mathrm{de}}$ did not exceed $5 \%$.

\section{Results and discussion}

In our experiments we recorded the distances passed by the drop in the FCM's layer (progress depth $h$ ). The main significant factors of the studied processes were the initial droplets' sizes (volumes) and the FCM's temperature. Table 1 shows approximate expressions for the experimental results, which were obtained using thermocouple measurements and high-speed video recording.

Table 1. Approximation correlations to calculate distances that were passed by water droplets of different volumes in the FCM layer depending on time.

\begin{tabular}{|c|c|c|c|}
\hline \multirow{3}{*}{ Droplets' volumes } & $\begin{array}{c}\text { During pyrolysis } \\
\text { process }\end{array}$ & \multicolumn{2}{|c|}{ Without pyrolysis process } \\
\cline { 2 - 4 } & \multicolumn{3}{|c|}{ Registration scheme } \\
\cline { 2 - 4 } & $\begin{array}{c}\text { Thermocouple } \\
\text { measurements }\end{array}$ & $\begin{array}{c}\text { Thermocouple } \\
\text { measurements }\end{array}$ & $\begin{array}{c}\text { High-speed video } \\
\text { recording }\end{array}$ \\
\hline $\begin{array}{c}V_{\mathrm{d}} \approx 90 \mu L- \\
R_{\mathrm{d}} \approx 2.8 \mathrm{~mm}\end{array}$ & $\begin{array}{c}h=3.5911 \cdot \ln (t)+7.164 \\
1\end{array}$ & $h=3.4618 \cdot \ln (t)+6.9894$ & $h=4,3785 \cdot \ln (t)+15.424$ \\
\hline $\begin{array}{c}V_{\mathrm{d}} \approx 200 \mu L- \\
R_{\mathrm{d}} \approx 3.6 \mathrm{~mm}\end{array}$ & $h=19.77 \cdot \ln (t)+20.066$ & $h=21.163 \cdot \ln (t)+17.697$ & $h=9.3762 \cdot \ln (t)+44.685$ \\
\hline $\begin{array}{c}V_{\mathrm{d}} \approx 800 \mu L- \\
R_{\mathrm{d}} \approx 5.7 \mathrm{~mm}\end{array}$ & $h=44.166 \cdot \ln (t)+32.69$ & $h=48.808 \cdot \ln (t)+30.694$ & $h=27.983 \cdot \ln (t)+98.761$ \\
\hline
\end{tabular}

It should be mentioned that the process of high-temperature pyrolysis of FCM does not practically effect on penetration depth of droplets in FCM. It can be explained by high porosity of this kind of forest fuel (relative porosity of pine needles can reach 70-90\%). Gaseous products, which were formed during pyrolysis of needles, move in the opposite direction to the droplets and practically do not influence on their movement. It can also be concluded that the effect of mass forces is more significant than the effect of resistance forces to the drops' motion. Drops with volume of $800 \mu \mathrm{l}$ can pass through the entire layer of FCM (with thickness up to 60) losing up to 20-30\% of their initial mass. Analyzing the approximation correlations (Table 1), we can say, that large droplets have much higher velocities than the small ones. Small droplets are inhibited by the FCM structure elements. It happens because transverse and longitudinal dimensions of the elements are comparable with the diameters of relatively small droplets (with size up to $3 \mathrm{~mm}$ ).

Table 2 shows experimental results of droplet mass estimations after their passing through a layer of FCM during the thermal decomposition process. Parameter $\Delta m$ $\left(\Delta m=m_{\mathrm{d} 0}-m_{\mathrm{de}}\right)$ characterizes the mass changing during the passage through the FCM layer, taking into account the losses due to wetting of the pine needles and evaporation. 
Table 2. Dependence of the parameter $\Delta m$ on the initial mass of droplets.

\begin{tabular}{|c|c|c|}
\hline \multirow{2}{*}{$m_{\mathrm{d} 0}, \mathrm{~g}$} & $\begin{array}{c}|c| \\
\text { The passage of water } \\
\text { droplets through FCM } \\
\text { layer (without pyrolysis } \\
\text { process) }\end{array}$ & $\begin{array}{c}\text { The passage of water } \\
\text { droplets through FCM } \\
\text { layer (during pyrolysis } \\
\text { process) }\end{array}$ \\
\hline 0.225 & 0.139 & 0.141 \\
\hline 0.325 & 0.137 & 0.181 \\
\hline 0.425 & 0.154 & 0.227 \\
\hline 0.525 & 0.189 & 0.279 \\
\hline 0.625 & 0.243 & 0.337 \\
\hline 0.725 & 0.315 & 0.401 \\
\hline 0.825 & 0.407 & 0.472 \\
\hline
\end{tabular}

The experimental results in Table 2 show the amount of water, which is consumed on the endothermic phase conversion. It is worth mentioning that this amount increases with initial water mass growth. Such fact can be explained not so much by the intensification of the vaporization process (most likely, the water mass increase in the layer leads to the FCM's temperature decrease and a drop in evaporation rates), but because of growth of contact area between water and the FCM structure elements.

\section{Conclusions}

The obtained result leads to conclusion that suppression of the thermal decomposition processes of FCM are most effective at a certain (most likely, less than 4-5 mm) characteristic of droplets not very large in size. Also it was clarified that the most efficient water use for reducing the temperature in the layer of thermally decomposing FCM is achieved by using fine droplets.

The research was funded by the Russian Federation President Program (project No. MK1684.2017.8).

\section{References}

1. X.K. Xiao, B.H. Cong, X.S. Wang, K.Q. Kuang, Richard K.K. Yuen, G.X. Liao, J. Fire Sci., 29, 339 (2011)

2. S. McAllister, I. Grenfell, A. Hadlow, W.M. Jolly, M. Finney, J. Cohen, Fire Safety J. 51, 133 (2012)

3. Meenakshi Gupta, R. Rajora, S. Sahai, R. Shankar, Anjan Ray, S.R. Kale, Fire Safety J. 54, 130 (2012)

4. O.P. Korobeinichev, A.G. Shmakov, V.M., Shvartsberg, A.A. Chernov, S.A. Yakimov K.P. Koutsenogii, V.I. Makarov, Fire Saf. J. 51, 102 (2012)

5. J. Janiszewski, Metrol. Measur. Sys., 19, 797 (2012)

6. J. Janiszewski, Int. J. Solids Struct., 49, 1001 (2012)

7. Vysokomornaya O.V., Kuznetsov G.V., Strizhak P.A. Fire Safety J. 70, 61 (2014)

8. Glushkov D.O., Kuznetsov G.V., Strizhak P.A., Volkov R.S. Thermal Science, 20129 (2016) 